\title{
Artificial Light at Night: A New Challenge in Microphytobenthos Research
}

\author{
Elena Maggi ${ }^{1 *}$ and João Serôdio ${ }^{2}$ \\ 1 Dipartimento di Biologia, CoNISMA - Consorzio Nazionale Interuniversitario per le Scienze del Mare, Università di Pisa, \\ Pisa, Italy, ${ }^{2}$ Department of Biology and CESAM - Centre for Environmental and Marine Studies, University of Aveiro, Aveiro, \\ Portugal
}

Artificial light at night (ALAN) has been recently recognized as a globally widespread anthropogenic disturbance, characterized by different intensities and spectra, as well as spatial and temporal variability. Among marine organisms, those living on coastal areas are particularly exposed to artificial light. Some recent studies anticipated a potential for influences of ALAN on microphytobenthos (MPB) on rocky shores, either direct or indirectly mediated by trophic relationships. Here we emphasize the need for further investigations in different habitats, as well as on synergistic interferences with other stressors already impinging on coastal areas. The study of effects of ALAN poses new challenges in MPB research, including those related to the use of instruments for measuring both the light environment and the functioning of microbial

OPEN ACCESS

Edited by:

Katherine Dafforn,

Macquarie University, Australia

Reviewed by:

Damon Kai Bolton,

University of New South Wales, Australia

Stuart Rees Jenkins, Bangor University, United Kingdom

*Correspondence: Elena Magg elena.maggi@unipi.it

Specialty section: This article was submitted to Marine Ecosystem Ecology, a section of the journal Frontiers in Marine Science

Received: 30 November 2019 Accepted: 21 April 2020

Published: 15 May 2020

Citation:

Maggi E and Serôdio J (2020) Artificial Light at Night: A New Challenge in Microphytobenthos Research. Front. Mar. Sci. 7:329. doi: 10.3389/fmars.2020.00329 photoautotrophs at night, and to the development of common monitoring approaches and manipulative experiments.

Keywords: light pollution, microphytobenthos, light intensity, light spectrum, temporal and spatial variability, trophic relationships, multiple stressors, challenges in sampling

\section{INTRODUCTION}

Artificial light at night (ALAN) is one of the most recently recognized sources of anthropogenic disturbance, globally widespread on both terrestrial and aquatic environments (Falchi et al., 2016; Davies and Smyth, 2017). ALAN is tightly related to the rate of urban development. For centuries, people have tended to concentrate on coastal areas and at the current rate of human population growth the spatial extent and magnitude of light pollution on these areas is expected to increase. The ALAN phenomenon is mostly due to the presence of outdoor night lights; these affect the surrounding abiotic environment both directly, through light sources of variable intensity (from a few to more than 100 lux) and indirectly, through the formation of a skyglow. The skyglow is a diffuse light field of low intensity (0.3-0.5 lux) visible as a glowing dome over built up areas and extending its influence on sub-urban and rural sites (Gaston, 2018). The most common direct sources of ALAN affecting coastal communities are represented by fixed lamps distributed along coastal streets, promenades, ports and marinas and potentially impacting estuarine mudflats, sandy beaches, rocky shores or artificial structures (Figures 1A,B). The intensity of light originating from a lamp rapidly declines within a few meters; therefore, the spatial arrangement of a given number of fixed lamps can create a scenario of alternating low and high light intensity areas, resulting in marked spatial variability in light pollution at the scale of a few to tens of meters (Figure 1C). It is worth noting that in coastal areas light pollution may also be related to the presence of intermitting and mobile sources, such as those associated with lighthouses or installed on commercial and tourist boats. The additional key feature of light sources, i.e., their emission spectrum, 


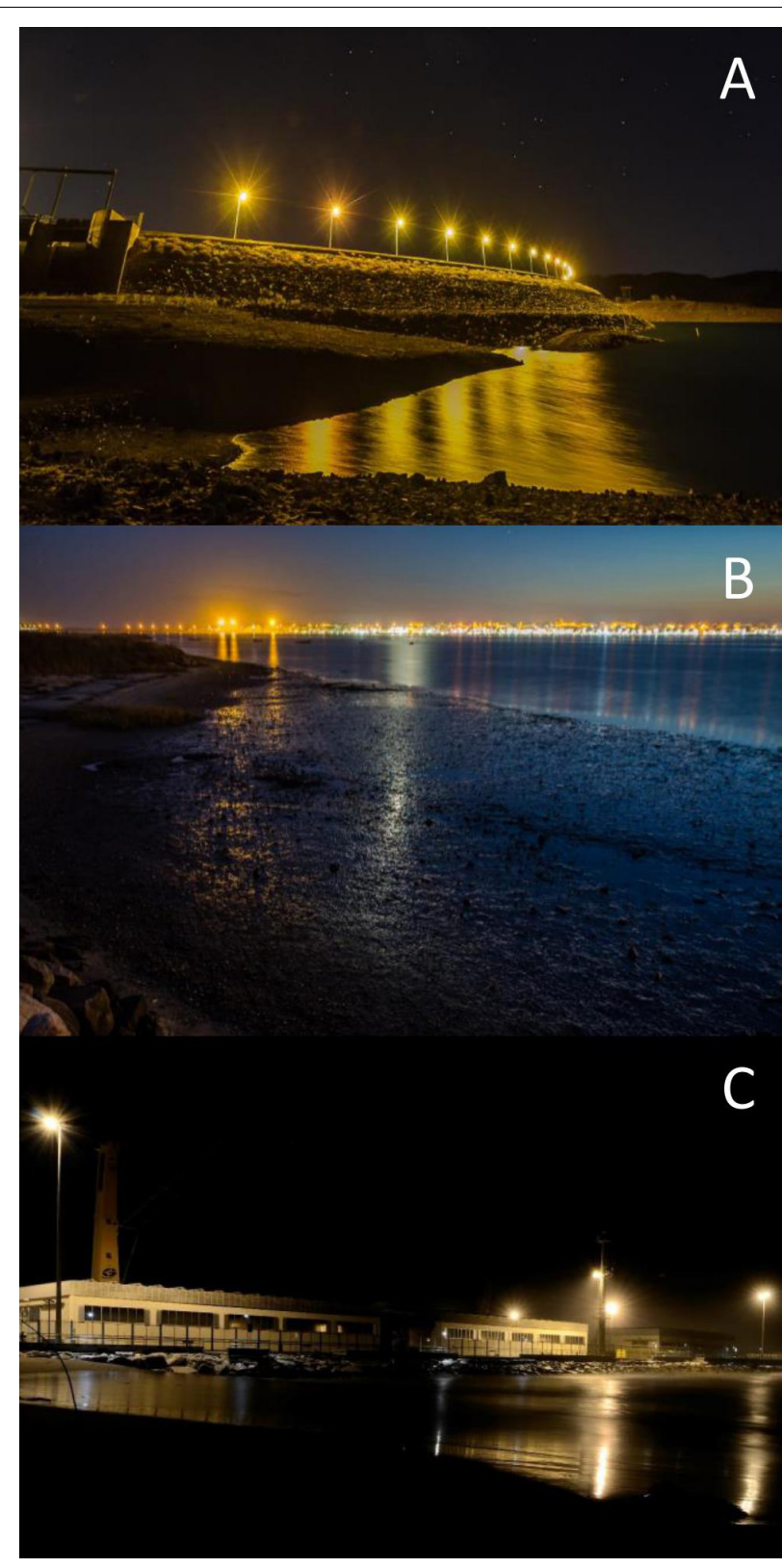

FIGURE 1 | Night light pollution caused by sources of artificial light located close (water damn, A) or relatively far away (intertidal estuarine mudflat, B), from water bodies and adjacent areas. (C) Example of alternating low and high intensity areas, along an artificial structure illuminated by streetlamps within a port. Photo credits: J. Serôdio (A,B) and M. Menconi (C).

may also create vertical variability in the water column, due to specific attenuation patterns among different wavelengths (Tamir et al., 2017).

Knowledge on the effect of ALAN on coastal organisms and habitats is still fragmented, but published research has already highlighted a variety of impacts, including effects on settlement processes (both in invertebrates and bacteria; Davies et al., 2015; Maggi and Benedetti-Cecchi, 2018), changes in behavior (e.g., orientation of turtles, vertical migration of zooplankton and fish, anti-predator and locomotor activities, trophic pressure; e.g., Witherington and Bjorndal, 1991; Underwood et al., 2017; Ludvigsen et al., 2018; Duarte et al., 2019; Maggi et al., 2019) and composition of assemblages (Garratt et al., 2019; Maggi et al., 2020).

Among these studies, first evidences exist of impacts on intertidal microphytobenthos (MPB) (Maggi and BenedettiCecchi, 2018), but there is a need to further address the role of light pollution on key physiological and ecological aspects of MPB in different coastal habitats.

\section{MICROPHYTOBENTHOS AND LIGHT ENVIRONMENT}

The MPB plays a key functional role in a variety of coastal systems, representing one of the main groups of primary producers and a source of food for grazers in intertidal and shallow subtidal systems, either on soft bottoms or hard surfaces (Underwood and Kromkamp, 1999; Jenkins et al., 2001; Nagarkar et al., 2004; Al-Zaidan et al., 2006). MPB comprises a mix of autotrophic taxa that uses light as the primary energy source for photosynthesis. While it is known that light optima vary among (groups of) MPB species (Oxborough et al., 2000; Frankenbach et al., 2018), knowledge about low light requirements is almost null. It is known that some marine photolithotrophs can grow under natural conditions characterized by no more than $10 \mathrm{nmol}$ photon $\mathrm{m}^{-2} \mathrm{~s}^{-1}$ (Raven et al., 2000). Although not aware of any experimental results, it is conceivable that motile diatoms might be capable of detecting and responding to low light levels, too; this hypothesis seems to be supported by the recent finding of phytochromes in pennate and centric diatoms (Fortunato et al., 2016). In fact, phytochromes can mediate the responses of plants to very low light intensities (e.g., "Very Low Fluence Responses" in seed germination; Sheerin and Hiltbrunner, 2017). Concerning motile diatoms, such responses would have a clear adaptive value in helping cells buried in ill-illuminated sediment layers (due to resuspension or bioturbation; Frankenbach et al., 2019) to reach the surface and regain photosynthetic activity and growth.

In addition to the role of light as a resource, seasonal changes in photoperiod play a fundamental role for MPB, the most obvious being related to the alternation between periods of high photosynthetic activity and net carbon fixation and those dominated by respiration. For cyanobacterial dominated MPB, the dark phase is also associated with the highest rates of nitrogen fixation (Sicora et al., 2019), while for MPB dominated by motile diatoms, common in fine sediment estuarine flats, these cycles are a main factor controlling diel vertical migrations (Round and Palmer, 1966; Consalvey et al., 2005; Coelho et al., 2011; Haro et al., 2019).

Given these premises, it is reasonable to expect that changes in night light conditions might affect MPB biology and ecology. Recent studies conducted in the Mediterranean showed, under lit conditions, a doubling in mean photosynthetic biomass and maximum photosynthetic efficiency of rocky shore MPB during early stages of the colonization process (Maggi and Benedetti-Cecchi, 2018), as well as an increase in temporal 
variability of maximum photosynthetic efficiency, more evident on mature assemblages (Maggi et al., 2019). These results clearly point out that ALAN originating by direct sources of white LEDs, at relatively high intensity (30 lux), may influence the mechanisms related to photosynthetic activity, as well as the competitive interactions among different species composing MPB assemblages. In fact, the observed temporal variability suggests the occurrence of changes in composition and/or relative abundances of different taxa, possibly related to differences in species-specific sensitivities to light and in light optima (Maggi et al., 2019). If and how these effects are geographically consistent and pervasive among different habitats is currently unknown. It is undeniable, however, the potential key role of ALAN in disrupting vertical migratory cycles and ultimately primary productivity, as observed in silty mud MPB assemblages after 3 days under continuous light conditions (Haro et al., 2019).

In addition to high intensity light sources, MPB might be impacted by low light levels of a few lux, such as those experienced at some distance from a streetlamp or induced by brief flashes of light due to intermittent/variable sources (e.g., lighthouses, boats), as suggested by the previous discussion on low light requirements. Moreover, recent findings have confirmed an increase in photosynthetic biomass in the planktonic cyanobacteria Microcystis aeruginosa under very low irradiance at night $\left(80 \mathrm{nmol} \mathrm{m} \mathrm{m}^{-2} \mathrm{~s}^{-1}, \sim 6.6 \mathrm{lux}\right)$ (Poulin et al., 2014).

As for different light spectra, the results of Grubisic et al. (2018) on freshwater periphyton assemblages suggest that the current transition from HPS lamps to white LEDs (Kyba, 2018) might increase the ecological impact of artificial light on aquatic primary producers.

Future investigations of ALAN effects on MPB should also consider the role of temporal variability. In fact, even constant artificial night lighting may have temporally variable effects. Hölker et al. (2015) revealed how natural seasonal changes in microbial community structure of freshwater habitats can be reduced under long-term lit conditions, with a shift from negative to positive net ecosystem production (NEP), driven by positive effects on the autotrophic component. Moreover, ALAN itself can be characterized by a marked temporal variability. For example, in some coastal localities, tourist activities are mainly concentrated during the warm season and light pollution originating from restaurants, beach resorts or boats might vary seasonally in intensity, spectrum and spatial variability.

Finally, the ecological effect of ALAN on MPB cannot be fully assessed without considering top-down and bottom-up effects related to their consumers (Leroux and Loreau, 2015; Lynam et al., 2017). Rates of grazing activity might be influenced by ALAN, with positive or negative effects cascading down to MPB, depending on the suppression or enhancement of consumers' metabolism, respectively (Maggi and Benedetti-Cecchi, 2018; Maggi et al., 2020). Potential changes in behavior of herbivores might even affect the spatial variability in the MPB biomass, as observed under increased water temperature (Como et al., 2014). Conversely, the effects on MPB might cascade up to their consumers, as an increase or decrease in availability of resources (Manfrin et al., 2018).

\section{ALAN: AN ADDITIONAL STRESSOR IMPINGING ON COASTAL ASSEMBLAGES}

Marine systems, including coastal ones, are currently impacted by a variety of global and local stressors, which can affect single organisms up to entire habitats in additive, synergistic or antagonistic ways (Halpern et al., 2008). ALAN is among the most recently recognized sources of anthropogenic disturbance in these areas and may interfere synergistically with various other stressors, such as the release of contaminants and waste (including plastic debris), eutrophication and warming. So far, very little is known about the possible interaction pathways of light pollution with other disturbances impinging on aquatic systems. To the best of our knowledge, the study by $\mathrm{Pu}$ et al. (2019) is the only one addressing this issue and highlighting the potential role of ALAN in alleviating the toxic effect of silver nanoparticles on litter decomposition in freshwater habitats. ALAN modified the dissolved concentration of AgNP by releasing the activity of decomposers' enzymes (inhibited by silver nanoparticles) and changing the microbial aquatic assemblage. Similarly, ALAN might modify the effect of other stressors usually covarying with light pollution in urban areas, such as eutrophication, changes in temperature due to the "heat island effect" or plastic debris (Grimm et al., 2008; Halfwerk and Slabbekoorn, 2015; Kirstein et al., 2019). Although not corroborated by any experimental data so far, the formulation of these hypotheses is supported by the knowledge that light is able to affect MPB growth in interaction with temperature and nutrients (e.g., Pivato et al., 2019; Rakotomalala et al., 2019). As for light and temperature, a recent study showed their key role for the development of biofilm on plastic debris, especially its photoautotrophic component (Misic and Covazzi Harriague, 2019). It is therefore possible that artificial light available at night might represent an additional factor shaping MPB colonizing these artificial substrates, and potentially interacting with resident MPB assemblages either in sandy, muddy or rocky coastal environments.

\section{CHALLENGES IN SAMPLING ACTIVITIES}

The study of potential ALAN effects on MPB poses several challenges regarding sampling activities. First, measurements of intensity and spectrum of ALAN in the field may be not as straightforward as in other situations. In fact, there is a limited availability of instruments specifically designed for measuring the light environment of microbial photoautotrophs in aquatic coastal habitats, where both water, sedimentation and presence of natural or artificial surfaces reflecting or absorbing light may create environmental heterogeneity at the scale of a few centimeters. Second, sampling and measurements of MPB under 
night conditions require attention to avoid even short exposure to light, with the risk of triggering additional responses and confounding the effects of ALAN under study. A particularly relevant case regards the use of Pulse Amplitude Modulation (PAM) fluorometry (Schreiber et al., 1986), a technique extensively used to study MPB biofilms on tidal systems, both for measuring photo-physiological and productivity-associated parameters (Kromkamp et al., 1998; Consalvey et al., 2005), but also short-term variations in surface MPB biomass associated to migratory rhythms (Serôdio et al., 1997). This technique relies on the application of light pulses, of very low (measuring light) and very high intensity (saturation pulses) that, while considered non-invasive in most other experimental contexts, might confound the detection of effects and responses to ALAN. Considering the potential response of MPB species to even low light levels, we propose that the use of PAM fluorometry in the context of ALAN studies should be preceded by preliminary tests for possible artefactual effects and the eventual adaptation of currently applied experimental protocols. Preliminary tests should be carried out comparing different instrument settings, namely light intensity, frequency, and color (most portable instruments use only blue or red LEDs) used for both measuring light and saturating pulses, on the triggering of upward vertical migration or photo-physiological effects. It seems prudent to recommend that measurements of ALAN effects should be carried out on samples not previously exposed to instrument lights, and that all measurements required for optimization of instrument settings should be carried out on a separate set of samples.

To fill in the gaps of a still fragmented and local knowledge of the ALAN effect on MPB, we should aim at developing integrated common monitoring approaches to data collection. This might involve the optimization of available sensors, sensitive enough to measure ALAN-levels in heterogeneous environments such as coastal areas; as well as of instruments for non-destructive quantification of MPB biomass and functioning. Finally, research activities might include experimental manipulative studies, both in the field and under laboratory conditions, to unambiguously assess the potential effects of different light intensities, spectra, duration but also timing of night light application on MPB in different coastal habitats. In fact, variable effects might be related, among others, to the variability in natural night lighting caused by changing moon phases. It is known that

\section{REFERENCES}

Al-Zaidan, A. S. Y., Kennedy, H., Jones, D. A., and Al-Mohanna, S. Y. (2006). Role of microbial mats in Sulaibikhat Bay (Kuwait) mudflat food webs: evidence from d13C analysis. Mar. Ecol. Prog. Ser. 308, 27-36. doi: 10.3354/meps308027

Caspers, H. (1984). Spawning periodicity and habitat of the Palolo worm eunice viridis (Polycheta, Eunicidae) in the Samoan islands. Mar. Biol. 79, 229-236. doi: 10.1007/BF00393254

Coelho, H., Vieira, S., and Serôdio, J. (2011). Endogenous versus environmental control of vertical migration by intertidal benthic microalgae. Eur. J. Phycol. 46, 271-281.

Como, S., Lefrancois, C., Maggi, E., Antognarelli, F., and Dupuy, C. (2014). Behavioral responses of juvenile golden gray mullet Liza aurata to changes in information driven by moonlight is used as a cue by some organisms in aquatic habitats, such as corals and the Palolo worm for spawning (Caspers, 1984; Harrison et al., 1984), or zooplankton for ocean-scale mass vertical migration during Arctic winter (Last et al., 2016). For many other aquatic organisms characterized by relatively short life cycles (such as $\mathrm{MPB}$ ), the potential role of chronobiology by moonlight has still not been elucidated and its study could reveal unexpected temporally variable effects of ALAN on different processes and mechanisms (Kronfeld-Schor et al., 2013).

\section{DISCUSSION}

Intensity, spectrum, spatial and temporal variability of ALAN are key features of a recently recognized source of anthropogenic disturbance, that is impinging on coastal organisms at a global scale. The role of light pollution on physiological and ecological aspects of MPB is still in its infancy, but some recent studies anticipate a potential for either direct or indirect influences on the spatial and temporal variability of biomass and diversity of MPB assemblages, mediated by trophic relationships (Maggi and Benedetti-Cecchi, 2018; Maggi et al., 2019, 2020), as well as for interactive effects with additional stressors ( $\mathrm{Pu}$ et al., 2019). Here we emphasize the need for including ALAN among the new challenges in microphytobenthos research, through the development of common monitoring approaches and the unambiguous assessment of its potential effects on MPB by means of manipulative experiment.

\section{AUTHOR CONTRIBUTIONS}

EM and JS contributed to the conception of the study and approved the final submitted version. EM wrote the first draft of the manuscript.

\section{ACKNOWLEDGMENTS}

Thanks are due to FCT/MCTES for the financial support to CESAM (UIDP/50017/2020 + UIDB/50017/2020), through national funds.

coastal temperatures and consequences for benthic food resources. J. Sea Res. 92, 66-73. doi: 10.1016/j.seares.2013.10.004

Consalvey, M., Perkins, R. G., Paterson, D. M., Underwood, G. J. C., Tomists, D. I. A., and Paterson, M. (2005). PAM fluorescence: a beginners guide for benthic diatomists. Diatom Res. 20, 1-22.

Davies, T. W., Coleman, M., Griffith, K. M., and Jenkins, S. R. (2015). Night-time lighting alters the composition of marine epifaunal communities. Biol. Lett. 11:20150080. doi: 10.1098/rsbl.2015.0080

Davies, T. W., and Smyth, T. (2017). Why artificial light at night should be a focus for global change research in the 21th century. Glob. Chang. Biol. 24, 872-882. doi: $10.1111 /$ gcb. 13927

Duarte, C., Quintanilla-Ahumada, D., Anguita, C., Manriquez, P. H., Widdicombe, S., Pulgar, J., et al. (2019). Artificial light pollution at night (ALAN) disrupts the 
distribution and circadian rhythm of a sandy beach isopod. Environ. Poll. 48, 565-573. doi: 10.1016/j.envpol.2019.02.037

Falchi, F., Cinzano, P., Duriscoe, D., Kyba, C. C. M., Elvidge, D. G., Baugh, K., et al. (2016). The new world atlas of artificial night sky brightness. Sci. Adv. 2:377. doi: 10.1126/sciadv. 1600377

Fortunato, A. E., Jaubert, M., Enomoto, G., Bouly, J. P., Raniello, R., Thaler, M., et al. (2016). Diatom phytochromes reveal the existence of far-red-lightbased sensing in the ocean. Plant Cell 28, 616-628. doi: 10.1105/tpc.15. 00928

Frankenbach, S., Azevedo, A. A., Reis, V., Dias, D., Vaz, L., Dias, J. M., et al. (2019). Functional resilience of PSII, vertical distribution and ecosystem-level estimates of subsurface microphytobenthos in estuarine tidal flats. Cont. Shelf Res. 182, 46-56. doi: 10.1016/j.csr.2019.05.018

Frankenbach, S., Schmidt, W., Frommlet, J., and Serôdio, J. (2018). Photoinactivation, repair and the motility-physiology trade-off in microphytobenthos. Mar. Ecol. Prog. Ser. 601, 41-57. doi: 10.3354/meps12670

Garratt, M. J., Jenkins, S. R., and Davies, T. W. (2019). Mapping the consequences of artificial light at night for intertidal ecosystems. Sci. Total Environ. 691, 760-768. doi: 10.1016/j.scitotenv.2019.07.156

Gaston, K. J. (2018). Lighting up the nighttime. Science 362:8226. doi: 10.1126/ science.aau8226

Grimm, N. B., Golubiewski, N. E., Faeth, S. H., and Redman, C. L. (2008). Global change and the ecology of cities. Science 319, 756-760. doi: 10.1126/science. 1150195

Grubisic, M., van Grunsven, R. H. A., Manfrin, A., Monaghan, M. T., and Holker, F. (2018). A transition to white LED increases ecological impacts of nocturnal illumination on aquatic primary producers in a lowland agricultural drainage ditch. Environ. Poll. 240, 630-638. doi: 10.1016/j.envpol.2018.04.146

Halfwerk, W., and Slabbekoorn, H. (2015). Pollution going multimodal: the complex impact of the human-altered sensory environment on animal perception and performance. Biol. Lett. 11:20141051. doi: 10.1098/rsbl.2014. 1051

Halpern, B. S., Walbridge, S., Selkoe, K. A., Kappel, C. V., Micheli, F., D’Agrosa, C., et al. (2008). A global map of human impact on marine ecosystems. Science 319, 948-952. doi: 10.1126/science.1149345

Haro, S., Bohórquez, J., Lara, M., Garcia-Robledo, E., González, C. J., Crespo, J. M., et al. (2019). Diel patterns of microphytobenthic primary production in intertidal sediments: the role of photoperiod on the vertical migration circadian rhythm. Sci. Tot. Env. 9:13376. doi: 10.1038/s41598-019-49971-8

Harrison, P. L., Babcock, R. C., Bull, G. D., Oliver, J. K., Wallace, C. C., and Willis, B. L. (1984). Mass spawning in tropical reef corals. Science 223, 1186-1189. doi: $10.1126 /$ science.223.4641.1186

Hölker, F., Wurzbacher, C., Weißenborn, C., Monaghan, M. T., Holzhauer, S. I. J., and Premke, K. (2015). Microbial diversity and community respiration in freshwater sediments influenced by artificial light at night. Philso. Trans. R. Soc. B 370:20140130. doi: 10.1098/rstb.2014.0130

Jenkins, S. R., Arenas, F., Arrontes, J., Bussel, J., Castro, J., Coleman, R. A., et al. (2001). European-scale analysis of seasonal variability in limpet grazing activity and microalgal abundance. Mar. Ecol. Prog. Ser. 211, 193-203. doi: 10.3354/ meps 211193

Kirstein, I. V., Wichels, A., Gullans, E., Krohne, G., and Gerdts, G. (2019). The Plastisphere - Uncovering tightly attached plastic "specific" microorganisms. PLoS One 14:e215859. doi: 10.1371/JOURNAL.PONE.0215859

Kromkamp, J., Barranguet, C., and Peene, J. (1998). Determination of microphytobenthos PSII quantum yield efficiency and photosynthetic activity by means of variable chlorophyll fluorescence. Mar. Ecol. Prog. Ser. 162, 45-55.

Kronfeld-Schor, N., Dominoni, D., de la Iglesia, H., Levy, O., Herzog, E. D., Dayan, T., et al. (2013). Chronobiology by moonlight. Proc. Biol. Sci. 280:20123088. doi: $10.1098 /$ rspb.2012.3088

Kyba, C. C. M. (2018). Is light pollution getting better or worse? Nat. Astron. 2, 267-269. doi: 10.1038/s41550-018-0402-407

Last, K. S., Hobbs, L., Berge, J., Brierley, A. S., and Cottier, F. (2016). Moonlight drives ocean-scale mass vertical migration of zooplankton during the Arctic winter. Curr. Biol. 26, 244-251. doi: 10.1016/j.cub.2015.11.038

Leroux, S. J., and Loreau, M. (2015). "Theoretical perspectives on bottom-up and top-down interactions across ecosystems," in Trophic Ecology. Bottom-Up and Top-Down Interactions across Aquatic and Terrestrial Systems, eds T. C.
Hanley and K. J. La Pierre (Cambridge: Cambridge University Press), 3-28. doi: 10.1017/CBO9781139924856.002

Ludvigsen, M., Berge, J., Geoffroy, M., Cohen, J. H., De La Torre, P. R., Nornes, S. M., et al. (2018). Use of an autonomous surface vehicle reveals small-scale diel vertical migrations of zooplankton and susceptibility to light pollution under low solar irradiance. Sci. Adv. 4:9887. doi: 10.1126/sciadv.aap9887

Lynam, C. P., Llope, M., Möllmann, C., Helaouët, P., Bayliss-Brown, G. A., and Stenseth, N. C. (2017). Interaction between top-down and bottom-up control in marine food webs. Proc. Nat. Acad. Sci. U.S.A. 114:201621037. doi: 10.1073/ pnas. 1621037114

Maggi, E., and Benedetti-Cecchi, L. (2018). Trophic compensation stabilizes marine primary producers exposed to artificial light at night. Mar. Ecol. Prog. Ser. 606, 1-5. doi: 10.3354/meps12769

Maggi, E., Bertocci, I., and Benedetti-Cecchi, L. (2019). Light pollution enhances temporal variability of photosynthetic activity in mature and developing biofilm. Hydrobiologia 847, 1793-1802. doi: 10.1007/s10750-019-04102-2

Maggi, E., Bongiorni, L., Fontanini, D., Capocchi, A., Dal Bello, M., Giacomelli, A., et al. (2020). Artificial light at night erases positive interactions across trophic levels. Funct. Ecol. 34, 694-706. doi: 10.1111/1365-2435.13485

Manfrin, A., Lehmann, D., Grunsven, R. H. A., Larsen, S., Syväranta, J., Wharton, G., et al. (2018). Dietary changes in predators and scavengers in a nocturnally illuminated riparian ecosystem. Oikos 127, 960-969. doi: 10.1111/oik.04696

Misic, C., and Covazzi Harriague, A. (2019). Development of marine biofilm on plastic: ecological features in different seasons, temperatures, and light regimes. Hydrobiologia 835, 129-145. doi: 10.1007/s10750-019-3934-7

Nagarkar, S., Williams, G. S., Subramanian, G., and Saha, S. K. (2004). Cyanobacteria-dominated biofilms: a high-quality food resource for intertidal grazers. Hydrobiologia 519, 89-94.

Oxborough, K., Hanlon, A. R. M., Underwood, G. J. C., and Baker, N. R. (2000). In vivo estimation of the photosystem II photochemical efficiency of individual microphytobenthic cells using high-resolution imaging of chlorophyll a fluorescence. Limnol. Oceanogr. 45, 1420-1425. doi: 10.4319/lo.2000.45.6.1420

Pivato, M., Carniello, L., Moro, I., and D’Odorico, P. (2019). On the feedback between water turbidity and microphytobenthos growth in shallow tidal environments. Earth Surf. Process. Landforms 44, 1192-1206.

Poulin, C., Bruyant, F., Laprise, M.-H., Cockshutt, A. M., Vandenhecke, J. M.R., and Huot, A. A. (2014). The impact of light pollution on diel changes in the photophysiology of Microcystis aeruginosa. J. Plankton Res. 36, 286-291. doi: 10.1093/plankt/fbt088

Pu, G., Zeng, D., Mo, L., He, W., Zhou, L., Huang, K., et al. (2019). Does artificial light at night change the impact of silver nanoparticles on microbial decomposers and leaf litter decomposition in streams? Environ. Sci. Nano. 2019, 1728-1739.

Rakotomalala, C., Guizien, K., Grangere, K., Lefebre, S., Dupuy, C., Orvain, M., et al. (2019). Modelling the functioning of a coupled microphytobenthic-EPSbacterial system in intertidal mudflats. Mar. Env. Res. 150:104754. doi: 10.1016/ j.marenvres.2019.104754

Raven, J. A., KÏbler, J. E., and Beardall, J. (2000). Put out the light, and then put out the light. J. Biol. Ass. UK 80, 1-25. doi: 10.1089/jwh.1998.7.297

Round, F. E., and Palmer, J. D. (1966). Persistent, vertical-migration rhythms in benthic microflora.: II. field and laboratory studies on diatoms from the banks of the river Avon. J. Biol. Assoc. 46, 191-214. doi: 10.1017/S0025315400017641

Schreiber, U., Schliwa, U., and Bilger, W. (1986). Continuous recording of photochemical and nonphotochemical chlorophyll fluorescence quenching with a new type of modulation fluorometer. Photosynth. Res. 10, 51-62. doi: 10.1007/BF00024185

Serôdio, J., Silva, J. M., and Catarino, F. (1997). Non-destructive tracing of migratory rhythms of intertidal benthic microalgae using in vivo chlorophyll a fluorescence. J. Phycol. 33, 542-553.

Sheerin, D. J., and Hiltbrunner, A. (2017). Molecular mechanisms and ecological function of far-red light signalling. Plant Cell Environ. 40, 2509-2529. doi: 10.1111/pce.12915

Sicora, C. I., Chiş, J., Chiş, C., and Sicora, O. (2019). Regulation of PSII function in Cyanothece sp. during a light-dark cycle. Photos. Res. 139, 461-473. doi: 10.1007/s11120-018-0598-5

Tamir, R., Lerner, A., Haspel, C., Dubinsky, Z., and Iluz, D. (2017). The spectral and spatial distribution of light pollution in the waters of the 
northern Gulf of Aqaba (Eilat). Sci. Rep. 7:42329. doi: 10.1038/srep 42329

Underwood, C. N., Davies, T. W., and Queiros, A. M. (2017). Artificial light at night alters trophic interactions of intertidal invertebrates. J. Anim. Ecol. 86, 781-789. doi: 10.1111/1365-2656.12670

Underwood, G. C. J., and Kromkamp, J. (1999). Primary production by phytoplankton and microphytobenthos in estuaries. Adv. Ecol. Res. 29, 93-153. doi: 10.1016/S0065-2504(08)60192-0

Witherington, B. E., and Bjorndal, K. A. (1991). Influences of artificial lighting on the seaward orientation of hatchling loggerhead turtles Caretta caretta. Biol. Conservat. 55, 139-149.
Conflict of Interest: The authors declare that the research was conducted in the absence of any commercial or financial relationships that could be construed as a potential conflict of interest.

Copyright (c) 2020 Maggi and Serôdio. This is an open-access article distributed under the terms of the Creative Commons Attribution License (CC BY). The use, distribution or reproduction in other forums is permitted, provided the original author(s) and the copyright owner(s) are credited and that the original publication in this journal is cited, in accordance with accepted academic practice. No use, distribution or reproduction is permitted which does not comply with these terms. 